\title{
Mechanical and Thermal Properties of Epoxy Polymer Composites Reinforced with $\mathrm{CuO}$
}

\author{
Mahadeva Raju G. K., ${ }^{\text {a, }}$, G. M. Madhuc, P Dinesh Sankar Reddy ${ }^{\mathrm{a}, \mathrm{d}}$, \\ Karthik K V ${ }^{\mathbf{b}}$ \\ ${ }^{a}$ Department of Chemical Engineering, Jawaharlal Nehru Technological University, \\ Anantapuram 515002, Andhra Pradesh, India \\ ${ }^{b}$ Department of Chemical Engineering, Dayananda Sagar College of Engineering, \\ Bangalore 560078, Karnataka, India \\ ${ }^{c}$ Department of Chemical Engineering, M S Ramaiah Institute of Technology, Bangalore \\ 560054, Karnataka India \\ ${ }^{d}$ National Institute of Technology, Andhra Pradesh, Bangalore 560 071, \\ Karnataka,India \\ ${ }^{e}$ Department of Chemical Engineering, Dayananda Sagar College of Engineering, \\ Bangalore 560078, Karnataka, India \\ , ${ }^{b}$ gkmking@gmail.com, ${ }^{c}$ gmmadhu@gmail.com, ${ }^{a, d}$ pdsreddy@gmail.com, \\ ${ }^{e} k v k 013 @ g m a i l . c o m$
}

\begin{abstract}
Polymer nano composites using $\mathrm{CuO}$ as filler material and epoxy as matrix materials were prepared with different concentrations of $\mathrm{CuO}$ nano particles (1-5 wt\%) by shear mixing followed by ultra-sonication process. The mechanical properties such as compressive strength and modulus were characterized using ASTM standards. It was found that the addition of $\mathrm{CuO}$ nano particles both compressive strength and modulus increased. As the $\mathrm{CuO}$ content increased in epoxy matrix the moduli values found to increase and were further analyzed using micromechanical models. The analytical models discussed correlate well with experimental values. The models discussed include Nicolais - Narkis, Turcsanyi, Piggot - Leidner and Nielsen models for the tensile strength values and for tensile modulus the models discussed include Halpin Tsai, Kerner and Sato - Furukawa models. These micromechanics models predict stiffness of nanocomposites with both aligned and randomly oriented fillers. XRD pattern revealed the interaction between $\mathrm{CuO}$ nanoparticles and epoxy matrix. The thermal decomposition behaviour revealed that there is an enhancement of onset of decomposition temperature by $28^{\circ} \mathrm{C}$ for $5 \mathrm{wt} \% \mathrm{CuO}$ filled epoxy than that of pure epoxy.
\end{abstract}

Keywords: $\mathrm{CuO}$; characterization ; mechanical properties; theroitcal models;

\footnotetext{
*Corresponding Author: gkmking@gmail.com
} 


\section{Introduction}

Over a last three decade nano composite materials have been the emerging materials among researchers. The volume and number of applications of composite materials have grown constantly, penetrating and conquering new markets relentlessly. Modern composite materials constitute a significant proportion of the engineering materials market ranging from everyday products to sophisticated applications. The current challenging is to make them cost effective. The efforts to produce economically attractive composite components have resulted in several innovative manufacturing techniques.

The composite industry has begins to recognize that the commercial applications of composites promise to offer much larger business opportunities than the aerospace sector due to the sheer size of transportation industry. Hence the shift of composite applications from aircraft to other commercial uses has been become prominent in recent years. The aerospace and defense industries will also benefit from new lightweight, high strength nanocomposite materials. Composites are able to meet the design requirements with significant weight savings as well as high strength-to-weight ratio as compared to non-renewable materials. High quantity of filler is needed in typical composites to impart desired properties, whereas the nanocomposite possess high thermo-mechanical properties with the addition of small quantity of fillers. Among the thermoset resins, epoxy resin is the conventional polymer with properties like chemical resistance, high stiffness and corrosion resistance. The properties of the resin can be modified by the incorporation of organic/inorganic fillers with different surface morphology and surface properties. The researchers have studied many fillers like carbon nanotubes [1-2], $\mathrm{Al}_{2} \mathrm{O}_{3}$ [3], $\mathrm{SiO}_{2}$, [4-5] $\mathrm{TiO}_{2}$ [6], $\mathrm{ZrO}_{2}$ [7] etc., $\mathrm{CuO}$ are found to be one of the excellent nano reinforcements for polymers, because of its high intercalation chemistry, high aspect ratio, ease of availability and low cost.

Some researchers have already studied the mechanical and thermal properties of epoxy Cuo composites which depends on the different weight percentage of filler materials. Huei Ruey Ong et al.[8] had reported that tensile and flexural decreased value for blank and increases by adding $\mathrm{CuO}$ particles. $\mathrm{O}$ Zabihi et al.[9] studied thermal Characterization and Thermo-Oxidative degradation. J K Rao et al.[10] also investigated the effect of $\mathrm{CuO}$ particles on the mechanical properties of PVA films when used as reinforcement. It was found that there was a significant increase in the tensile properties of PVA films. It was also observed that PVA films containing $2 \mathrm{wt} \%$ of $\mathrm{CuO}$ nanoparticles exhibited the highest tensile properties.

\section{Experimental}

\subsection{Materials Used}

Lapox L 12 was used as an epoxy resin which was procured from Atul Ltd. Polymers division, Gujarat, India. Lapox L12 is a liquid epoxy resin of average viscosity which can be employed with many hardeners for manufacturing glass fiber reinforced composites.K-6 was used as hardener at room temperature which has low viscosity. 
Being rather reactive, it has a small pot life and will rapidly cure at normal ambient temperatures. $\mathrm{CuO}$ nano particles were synthesized using solution combustion method.

\subsection{Mould Preparation}

The mould was made of silica, as the epoxy doesn't stick to it even after curing. Two silica sheets were of $10 \mathrm{~mm}$ and $3 \mathrm{~mm}$ in thickness were used respectively. Two $20 \mathrm{x} 10$ $\mathrm{cm}$ rectangular holes were made on the $10 \mathrm{~mm}$ thick sheet as shown in the Figure 1. This sheet was then placed on top of the $3 \mathrm{~mm}$ thick silica sheet, which acted as a base plate. These sheets were mounted on top of a wooden platform which served as a support. This whole setup was screwed together with the help of a metal sheet mounted on top of the silica sheets.

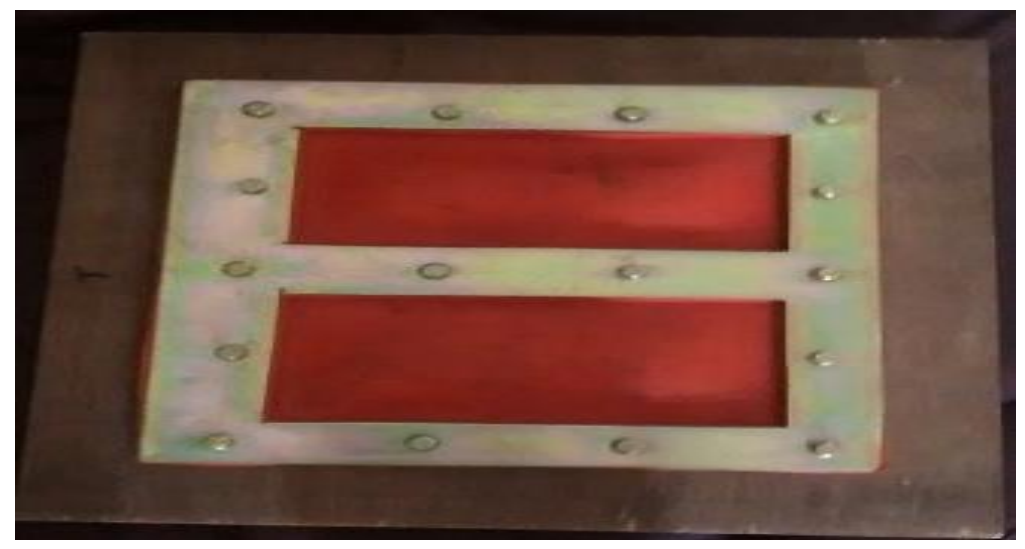

Figure 1: Fabrication of silica platform

\subsection{Fabrication of Epoxy nanocomposites}

$90 \mathrm{ml}$ of Lapox L 12 was added to $10 \mathrm{ml}$ of the hardener $\mathrm{K} 6$ and made as a spread sheet of dimension $20 \times 10 \times 0.5 \mathrm{~cm}$. The slab was casted with solution loaded with varying percentage of $\mathrm{CuO}$ nano particles and they are subjected for ultra-sonication at $65^{\circ} \mathrm{C}$ for $60 \mathrm{~min}$ and cooled to room temperature. The casted film containing $\mathrm{CuO}$ nano particles are dispersed evenly in the epoxy matrix was then poured into the silica mould prepared and was allowed to cure for $24 \mathrm{hrs}$ and after curing the mould was subjected for compressive strength and compressive modulus tests. The experiment was repeated by varying percentage of $\mathrm{CuO}$. The stoichiometric weights of the precursors taken to prepare the different samples compositions are given in Table 1.

Table 1: Composition of $\mathrm{CuO}$ in the matrix

\begin{tabular}{|c|c|c|c|}
\hline Epoxy $(\mathrm{ml})$ & Hardener $(\mathrm{ml})$ & $\% \mathrm{CuO}$ & $\mathrm{CuO}(\mathrm{gm})$ \\
\hline 90 & 10 & $1 \%$ & 1.12 \\
\hline 90 & 10 & $2 \%$ & 2.24 \\
\hline 90 & 10 & $3 \%$ & 3.36 \\
\hline 90 & 10 & $4 \%$ & 4.48 \\
\hline 90 & 10 & $5 \%$ & 5.6 \\
\hline
\end{tabular}




\subsection{X-Ray Diffraction (XRD)}

XRD analysis was reported using Rigaku-Smart Lab Diffractometer. The specimen of unvarying thickness was seated on the sample holder and the X-ray tracings were reported in the range of $0^{\circ}$ to $80^{\circ}$ per min.

\subsection{Morphology Study (SEM)}

The surface morphology and filler dispersion was observed from SEM micrographs of the composites. The surface images were captured using Scanning Electron Microscope $(\mathrm{SEM})($ Ultra $55 \mathrm{Carl}$ Zeiss Model) operating at a voltage of $5 \mathrm{kV}$.

\subsection{Thermogravimetric analysis}

TGA was carried out for the composites using TA instrument (Model Q500, UK). The composites were subjected to a heating rate of $10^{\circ} \mathrm{C}$ per min in a heating range of $25-$ $750{ }^{\circ} \mathrm{C}$ in nitrogen atmosphere.

\subsection{Compression Properties}

The compressive strength and modulus studies for the composites were carried out using Kudale UTM (Model PC-2000) at a cross head speed of $5 \mathrm{~mm} / \mathrm{min}$ and $2 \mathrm{~mm} / \mathrm{min}$ respectively. The compression tests were performed as per ASTM: D 695 method.

\section{Results and Discussions}

\subsection{X-Ray Diffraction (XRD)}

The crystalline nature of pure nano $\mathrm{CuO}$ was observed by various sharp peaks shown by the XRD patterns in the fig 2a. The distinct diffraction peaks can be seen at 2 theta values of $32.56^{\circ}, 35.59^{\circ}, 38.82^{\circ}, 48.24^{\circ}, 53.50^{\circ}, 58.41^{\circ}, 61.56^{\circ}, 68.10^{\circ}, 72.42^{\circ}$ and $75.28^{\circ}$ for $\mathrm{CuO}$. [16].
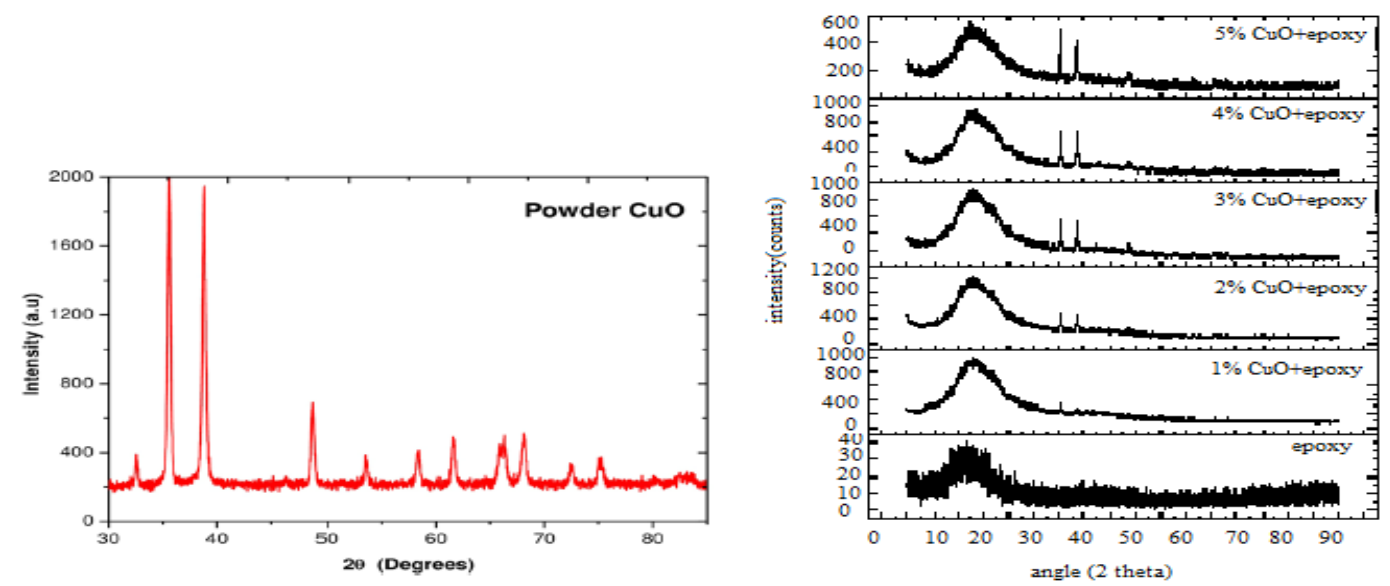

Figure 2a: XRD image a: Pure CuO nanoparticles. b: Pure Epoxy and Epoxy +(1 wt\% - 5wt\% CuO)

\subsection{Morphology study using Scanning Electron Microscope (SEM) analysis}

It was observed that at lower concentrations of $\mathrm{CuO}$ the nanoparticle distribution through the matrix was homogenous. But as the nanofiller concentration increased agglomeration of the nanoparticles was observed. Due to this agglomeration there was an increase in 
particle size as the filler concentration increased. The $\mathrm{CuO}$ particles can be seen as white spots in all the images.

(a)

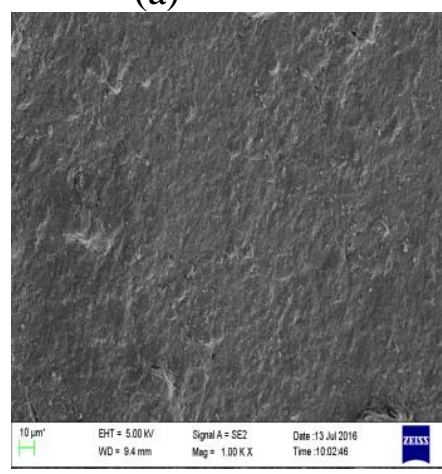

(d)

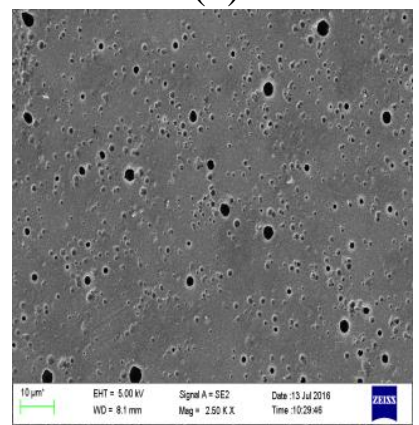

(b)

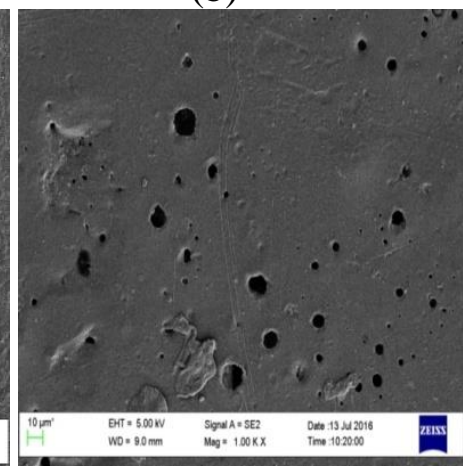

(e)

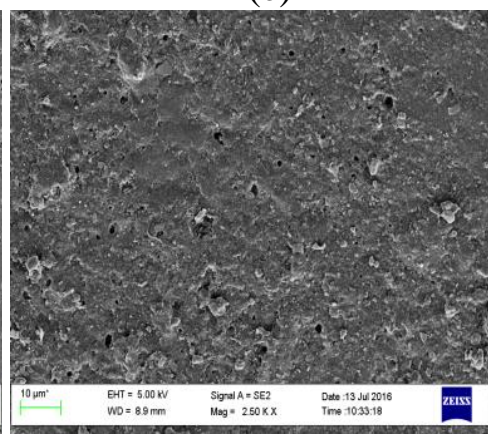

(c)

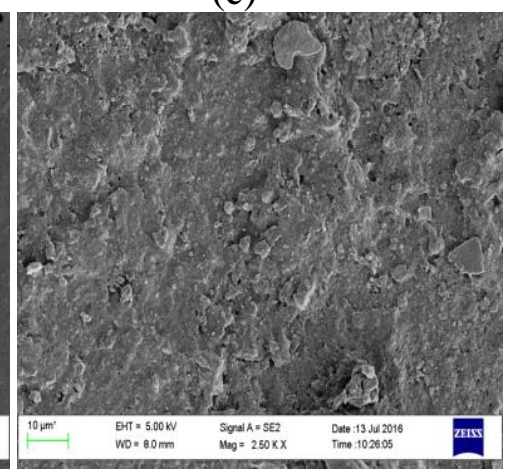

(f)

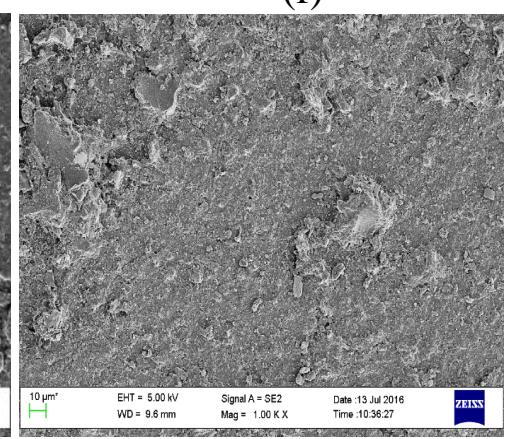

Figure.3.Scanning Electron Microscope (SEM) images of epoxy loaded with $\mathrm{CuO}$

(a) Pure Epoxy (b-f) Pure Epoxy $+(1 \mathrm{wt} \%$ to $5 \mathrm{wt} \% \mathrm{CuO})$

3.3 Thermo gravimetric analysis(TGA)

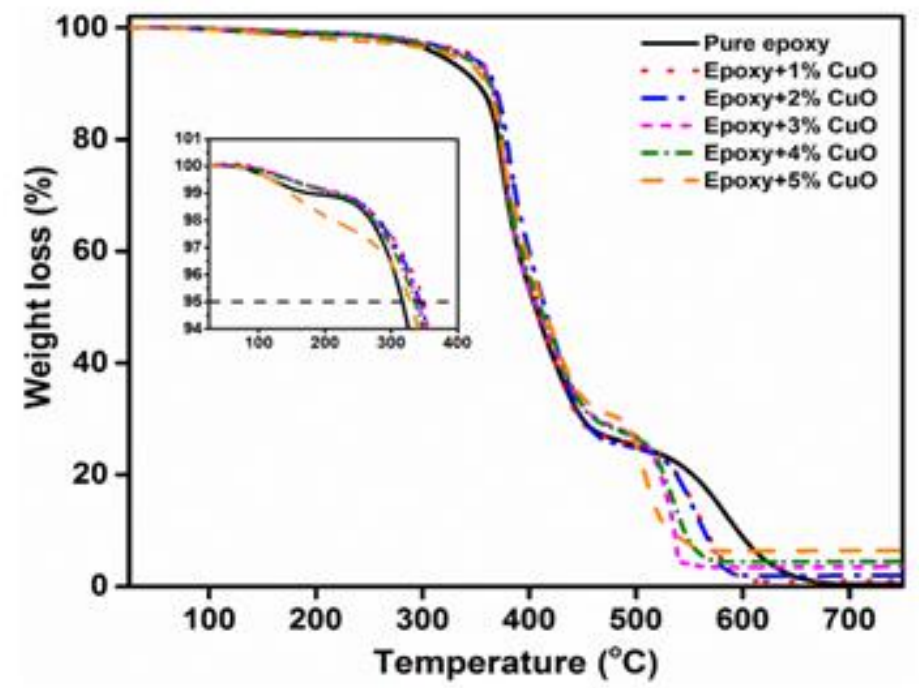

Figure 4 TGA thermograms of Pure Epoxy and Pure Epoxy + ((1wt\% to 5 wt\% $\mathrm{CuO})$

The Thermo gravimetric analysis was carried as per the procedure outline in the ASTM D 3850-94. In order to examine the thermal stability, thermal analyses were carried out on epoxy/CuO composites. The results were compared with pure epoxy. Fig.4 shows the thermograph recorded for the pure epoxy and for epoxy/CuO composites ( 1 to $5 \mathrm{wt} \%$ ). It 
has been observed that there is a change in the thermal degradation behavior of epoxy with $\mathrm{CuO}$. The onset of decomposition temperature has increased as the $\mathrm{CuO}$ filler content increased in epoxy. The onset of decomposition temperature (temperature at 5\% weight loss) was found to increase for the composites under study. The decomposition temperature onset accompanied by $5 \%$ weight loss for epoxy/flyash- $2 \mathrm{wt} \%$ is $345^{\circ} \mathrm{C}$ and for pure epoxy it is $317^{\circ} \mathrm{C}$. The onset of decomposition temperature is higher by $28^{\circ} \mathrm{C}$ than that of pure epoxy. The initial weight loss between $100-200^{\circ} \mathrm{C}$ for the all the samples indicates the escape of volatile matters present in the samples which could be entrapped during fabrication process. The TGA analysis reveals that the decomposition begins after $290^{\circ} \mathrm{C}$ for all the samples.

\subsection{Mechanical Properties}

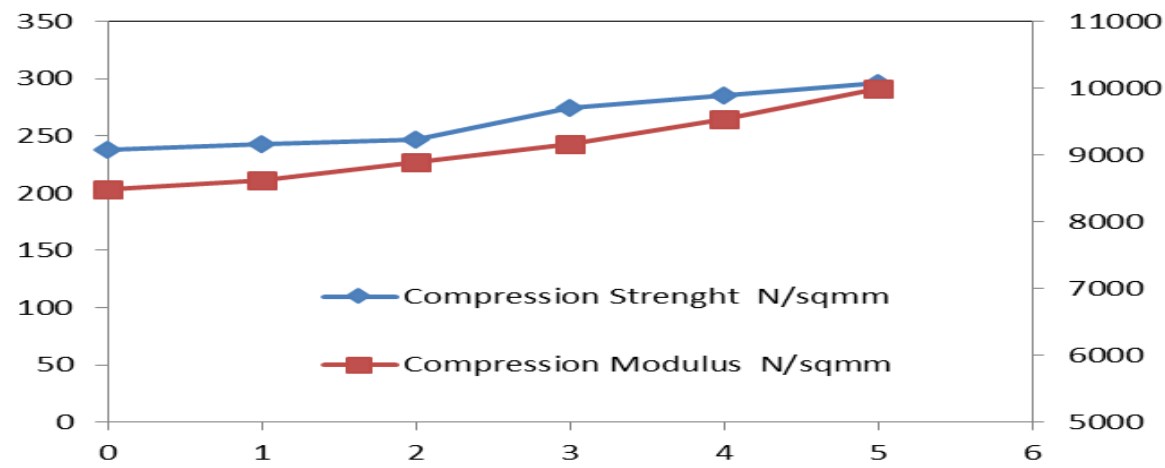

Figure 5 Compressive strength and modulus of Epoxy $+((1 w t \%$ to $5 \mathrm{wt} \% \mathrm{CuO})$

Figure 5 shows the compressive strength and compressive modulus of the composite versus percentage $\mathrm{CuO}$ loading. The addition of $\mathrm{CuO}$ both compressive strength and modulus increases the linearly. The highest compressive strength was observed at $5 \mathrm{wt} \%$ of $\mathrm{CuO} /$ epoxy nanocomposite specimen.

Relative Compressive Modulus (RCM) of Epoxy/CuO composite

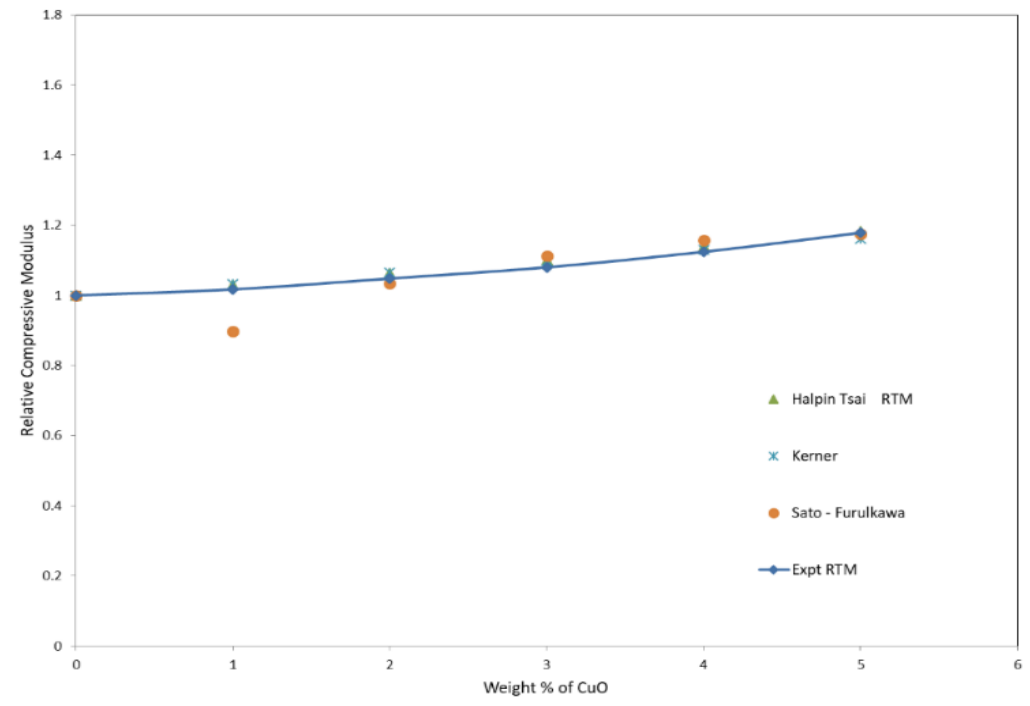

Figure 7: Plot of wt\% of $\mathrm{CuO}$ versus relative compressive modulus of composites 
Fig.7 shows the plot of weight percentage of $\mathrm{CuO}$ versus relative compressive modulus. The RCM for the composites reaches an optimum value with $5 \mathrm{wt} \% \mathrm{CuO}$ loading. Further analysis of the experimental results was done using empirical models.

The first is Kerner's model [18] given as follows (Equation 8).

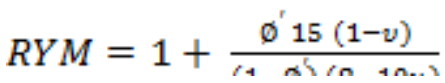

In the above equation, $v$ is Poisson's ratio of the epoxy taken to be 0.33 [19].

The second model used is the Halpin-Tsai model and is given as follows (Equation 9 and 10).

$R Y M=\left(\frac{3}{8} \frac{1+2 \phi^{s} \eta_{E}}{1-\eta_{E} \phi^{s}}+\frac{5}{8} \frac{1+2 \eta_{T} \phi^{s}}{1-\eta_{T} \phi^{s}}\right)$

Where,

$\eta_{e}=\frac{\delta-1}{\delta+2 A_{f}}, \quad \eta_{T}=\frac{\delta-1}{\delta+2}$

In the above equation, $\delta$ is the ratio of the nanofiller modulus to the matrix modulus without $\mathrm{CuO}$. The filler modulus is taken to be $40.33 \mathrm{GPa}$ [20]. The next is the SatoFurukawa model which incorporates an adhesion factor, $\xi$ value is 0 for perfect adhesion and 1.0 for no adhesion. The equation for this model is given below (Equation 11 and 12).

$R Y M=\left[1+\frac{\left(\phi^{\prime}\right)^{\frac{2}{a}}}{2-2\left(\phi^{s}\right)^{\frac{1}{a}}}(1-\psi \xi)-\frac{\left(\phi^{\prime}\right)^{2 / a} \psi \xi}{\left(1-\left(\phi^{\delta}\right)^{1 / \sqrt{a}}\right)\left(\phi^{s}\right)}\right.$

Where,

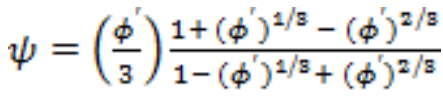

The values of $a, b$ and the characteristic parameter are given in Table 3. Both Kerner and the Halpin-Tsai model, neither the optimal nor the trend matched for $\mathrm{CuO}$ loading. However, Sato-Furukawa model showed a good match with the experimental values with a $\xi$ value of 0.24 which suggests good interactions between the blend components.

Table 3.Values of a, b and characteristic parameters for all the three models for relative compressive modulus

\begin{tabular}{lccc}
\hline Model & $\boldsymbol{a}$ & $\boldsymbol{b}$ & Parameter value \\
\hline Halpin Tsai & 2 & 2 & - \\
Kerner & 0.1 & 0.1 & - \\
Sato - Furukawa & 0.1 & 1 & $\xi=0.24$ \\
\hline
\end{tabular}

\section{Conclusion}

In this work, epoxy composite specimens were reinforced with $\mathrm{CuO}$. Lapox L12 was the chosen matrix for integrating $\mathrm{CuO}$. The $\mathrm{CuO}$ content was varied from $1 \%$ to $5 \%$ in the composites by weight and their effect on strength and modulus were observed. The 
surface morphology and the interactions between matrix and $\mathrm{CuO}$ were studied using SEM and XRD techniques. It was understood from SEM technique that $\mathrm{CuO}$ nanoparticles are porous and that they have tendencies to agglomerate at higher concentrations. The compression strength and modulus improved with the increase in $\mathrm{CuO}$ content. The mathematical models are well fit to the values .The decomposition temperature for $5 \%$ was $345^{\circ} \mathrm{C}$ and for pure epoxy it is $317^{\circ} \mathrm{C}$. This study demonstrates the possibility of developing advanced multi-scale composites which can be utilized in structural application by incorporating modicum of $\mathrm{CuO}$ particles.

\section{References}

[1]. Ahmaruzzaman M. A review on the utilization of fly ash. Progress in energy and combustion science. 2010 Jun 1;36(3):327-63.

[2]. Rai AK, Paul B, Singh G. A study on physico chemical properties of overburden dump materials from selected coal mining areas of Jharia coalfields, Jharkhand, India. International journal of environmental sciences. 2011;1(6):1350-60.

[3]. Sahay AN. R\&D initiatives in utilization of fly ash in coal sector. proc. of fly ash an opportunity for mining sector, New Delhi, India. 2010:26-35.

[4]. Kaniraj SR, Gayathri V. Permeability and consolidation characteristics of compacted fly ash. Journal of energy engineering. 2004 Apr;130(1):18-43.

[5]. Zhang J, Xu YC, Huang P. Effect of cure cycle on curing process and hardness for epoxy resin. Express Polymer Letters. 2009 Jun;3(9):534-41.

[6]. Chand N. SEM observation of fractured flyash-polyester composites. Journal of materials science letters. 1988 Jan;7(1):36-8.

[7]. Kulkarni SM, Sharathchandra S, Sunil D. On the use of an instrumented set-up to characterize the impact behaviour of an epoxy system containing varying fly ash content. Polymer testing. 2002 Jan 1;21(7):763-71.

[8]. Ong HR, Khan MM, Ramli R, Yunus RM. Effect of CuO nanoparticle on mechanical and thermal properties of palm oil based alkyd/epoxy resin blend. Procedia chemistry. 2015 Jan 1;16:623-31.

[9]. Zabihi O, Ghasemlou S. Nano-CuO/epoxy composites: thermal characterization and thermo-oxidative degradation. International Journal of Polymer Analysis and Characterization. 2012 Feb 1;17(2):108-21.

[10]. Nazarzade S, Ghorbani HR. Synthesis of CuO/Epoxy nanocomposites for the preparation of antifungal coating. Nanomedicine Journal. 2019;6(2):142-6.

[11]. Chaowasakoo T, Sombatsompop N. Mechanical and morphological properties of fly ash/epoxy composites using conventional thermal and microwave curing methods. composites science and technology. 2007 Sep 1;67(11-12):2282-91.

[12]. Nath DC, Bandyopadhyay S, Yu A, Blackburn D, White C. High strength biocomposite films of poly (vinyl alcohol) reinforced with chemically modified-fly ash. Journal of materials science. 2010 Mar;45(5):1354-60.

[13]. Anandhan S, Sundar SM, Senthil T, Mahendran AR, Shibulal GS. Extruded poly (ethylene-co-octene)/fly ash composites-value added products from an environmental pollutant. Journal of Polymer Research. 2012 Mar;19(3):1-1. 
[14]. Jordan, Jeffrey \& Jacob, Karl \& Tannenbaum, Rina \& Sharaf, Mohammed \& Jasiuk, Iwona. (2005). Experimental trends in polymer nanocomposites - A review. Materials Science and Engineering: A. 393.

[15]. Li, Zhe \& Xue, Huiwen \& Chen, Jen-Ping \& Wang, Wei-Chyung. (2016). Meteorological and Aerosol Effects on Marine Stratocumulus. Journal of the Atmospheric Sciences. 73. 151111130909008. 10.1175/JAS-D-15-0101.1.

[16]. Çelik, Özlem \& Damci, Erdem \& Pişkin, S.. (2008). Characterization of fly ash and it effects on the compressive strength properties of Portland cement. Indian Journal of Engineering and Materials Sciences. 15. 433-440.

[17]. Nicolais, Luigi and Moshe Narkis. "Stress-strain behavior of styreneacrylonitrile/glass bead composites in the glassy region." Polymer Engineering and Science 11 (1971): 194-199.

[18]. Jain, Manish \& Sastry, B. (2006). Fly Ash Properties and its Application in Mining Industry - A Critical Review.

[19]. Jadhao PD, Nagarnaik PB. Influence of polypropylene fibers on engineering behavior of soil- fly ash mixtures for road construction. Electronic Journal of Geotechnical Engineering. 2008;13:1-1.

[20]. Raju GM, Madhu GM, Khan MA, Reddy PD. Characterizing and modeling of mechanical properties of epoxy polymer composites reinforced with fly ash. Materials Today: Proceedings. 2018 Jan 1;5(14):27998-8007. 